\title{
Development of Security Engineering Curricula at US Universities
}

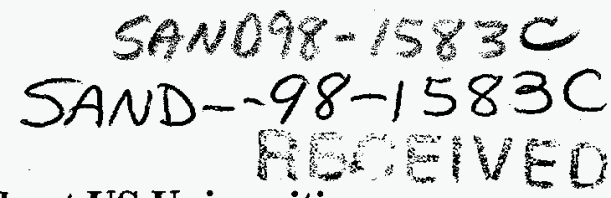

Mary Lynn Garcia

Sandia National Laboratories

AUG 121998

\section{ABSTRACT}

The Southwest Surety Institute was formed in June, 1996 by Arizona State University (ASU), New Mexico Institute of Mining and Technology (NM Tech), New Mexico State University (NMSU), and Sandia National Laboratories (SNL) to provide new educational programs in Security Engineering. This is the first science-based program of its kind in the United States, directed at educating Security Engineers to help government and industry address their security needs. Current courses include security system design, evaluation, principles, and technology, the criminal justice system, and explosives surety.

Each member brings a unique educational capability to the Institute. NMSU provides a Security Technology minor, merging programs in Criminal Justice and Electronics Technology. NM Tech has a formidable explosives testing and evaluation facility. ASU is developing a Masters program in Security Engineering at their School of Technology located on a new campus in Mesa, Arizona. The Sandia National Laboratories security system design and evaluation process forms the basis for the Security Engineering curricula. In an effort to leverage the special capabilities of each university, distance education will be used to share courses among Institute members and eventually with other sites across the country.

The Institute will also pursue research and development funding in the areas of physical security, information security, computer modeling and analysis, and counter-terrorist technology. Individual Institute members are currently working with sponsors from government and industry in areas such as counter-ierrorism, microelectronics, banking, aviation, and sensor development.

\section{INTRODUCTION}

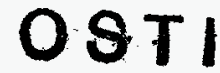

Recent highly visible attacks on the American public, including the World Trade Center, Oklahoma City, and the Centennial Olympic Park bombing at the Atlanta Olympics, have increased awareness of the necessity for good security systems planning and implementation. While the security industry as a whole can offer effective solutions to these problems, it is constrained by a lack of standard principles and methods by which to create solutions. This provides the opportunity for US universities to participate by creating new educational programs aimed at the development of a common understanding and approach to security system design. Several US universities have joined together to establish a new discipline of security engineering, incorporating basic concepts from criminal justice, technology, and business.

The Southwest Surety Institute was formed in June, 1996 by Arizona State University (ASU), New Mexico Institute of Mining and Technology (NM Tech), New Mexico State University (NMSU), and Sandia National Laboratories (SNL) to provide new educational programs in security engineering. In January 1998, Louisiana State University (LSU) also joined the Institute. These are the first science-based security education programs in the United States, directed at creating a new generation of security engineers to help government and industry address their security needs. The programs will emphasize the use of performance based systems to design and evaluate the effectiveness of security systems prior to implementation, thereby providing a business rationale for approval of proposed changes.

\section{UNIVERSITY PROGRAMS}

ASU-East offers a Masters program in Security Engineering Technology beginning in the fall of 1998 at their School of Technology, located on a new campus in Mesa, Arizona. The degree is open to graduates of appropriate programs in engineering and engineering technology, as well as graduates of traditional criminal justice programs who have an acceptable technical background. This includes 
graduates of the programs at schools belonging to the Southwest Surety Institute. The program is designed to be completed in three semesters and one summer. Students will begin the course of study in the Fall, with a target graduation by the end of the following summer. The program will include nine courses and an applied project, resulting in a total of 32 semester credit hours. Coursework includes Physical Security, Research Methods in Engineering, Risk Analysis, Instrumentation Systems, Forensic Technology, Security Law, Economic Analysis of Engineered Systems, and Computer Fraud.

In addition to the program described above, a set of normalization courses will be provided for those interested and otherwise qualified baccalaureate degree students with backgrounds that are lacking the technical basis necessary for the proposed program of study. The normalization sequence may be completed at any member institution of the Southwest Surety Institute. These normalization courses may be taken at the students' current university or at ASU. This structure will support the start of a class every Fall at ASU, with graduation from the program at the end of the following summer, assuming the student attends full time.

NM Tech and LSU have enhanced their existing resources and capabilities to develop a counterterrorism education program. NM Tech operates the Energetic Materials Research and Testing Center (EMRTC), which has counterterrorism research facilities and programs already in place. LSU trains approximately 15,000 first responders each year, through its Anti-Terrorist Training Assistance Program and Fire and Emergency Training Institute. The two universities have recently joined together to provide training to international law enforcement agencies, conducted cooperatively at both schools. The Academy for Counterterrorism Education (ACE) was developed in response to the growing threat of terrorist acts on US military forces and civilian populations. Terrorist bombings such as the Khobar Towers in Saudi Arabia and in Oklahoma City demonstrate this alarming threat. While the US is spending millions of dollars on counterterrorism and force protection technology, state and local first responders are unprepared to deal with large explosives devices and weapons of mass destruction. Federal, military, National Guard, state and local police, fire, medical, and other first responders need training to prevent, detect, and respond to terrorist attacks.
The goal of ACE is to provide first responders with counterterrorism training. ACE will conduct a series of short courses and seminars at NM Tech, LSU, and selected locations throughout the US. Planned courses of instruction include Emergency Response Managers and Commanders Seminar (3 days), Chem/Bio/Explosives Responder Trainers (5 days) and a Large Explosive Device Post-Blast Analysis Course (5 days). Other planned educational support activities include "take-home" training and specialized equipment packages, an on-line distance education resource center, and graduate assistance and internships to expand the domestic base of expertise. For current updates on $\mathrm{ACE}$, visit their homepage at www.emrtc.nmt.edu/acel.

Individually, both NM Tech and LSU are also developing programs incorporating security engineering curricula. NM Tech is implementing an option (minor) program that will include courses in shock physics, explosives chemistry, explosives engineering, and security technology. In addition, students enrolled in doctoral programs in science and engineering may add these courses to their program of study and increase their knowledge of security concepts. In support of the Southwest Surety Instiute educational goals and to exploit the unique capabilities offered by NM Tech, Explosives Surety Chemical Engineering 489, is currently offered via distance learning to NMSU and SNL; the course is expected to be offered at ASU as part of the MS program.

LSU is planning on an initial offering of a one week course entitled Design and Evaluation Process for Physical Security Systems in August of 1998 and will develop additional courses to supplement this program over time. The one week course, taught by experts from Sandia National Laboratories, will be repeated twice each year in the Baton Rouge area as part of LSU's continuing education program. These offerings allow access to the education and training programs of the Institute for those interested in continuing professional education or refresher training, such as law enforcement or industrial security managers.

NMSU offers a minor in security technology that merges existing courses from the department of Criminal Justice with new courses created in the Engineering Technology department. Creation of a supplemental undergraduate program is planned for the near future. These programs are only open to 


\section{DISCLAIMER}

This report was prepared as an account of work sponsored by an agency of the United States Government. Neither the United States Government nor any agency thereof, nor any of their employees, makes any warranty, express or implied, or assumes any legal liability or responsibility for the accuracy, completeness, or usefulness of any information, apparatus, product, or process disclosed, or represents that its use would not infringe privately owned rights. Reference herein to any specific commercial product, process, or service by trade name, trademark, manufacturer, or otherwise does not necessarily constitute or imply its endorsement, recom. mendation, or favoring by the United States Government or any agency thereof. The views and opinions of authors expressed herein do not necessarily state or reflect those of the United States Government or any agency thereof. 


\section{DISCLAIMER}

Portions of this document may be illegible in electronic image products. Images are produced from the best available original document. 
students currently enrolled in undergraduate programs at the university.

All of the above programs are based on the SNL design and evaluation methodology, with emphasis on performance-based systems. This approach has been used for the past 25 years at US Department of Energy facilities with responsibility for protecting critical nuclear assets. Emphasis is placed on systems engineering concepts including determination of objectives, design of the security system using detection, delay, and response elements, and evaluation of the design prior to implementation to test the design against the objectives. This systematic approach also integrates people, procedures and equipment to provide an effective security system that protects identified targets from the expected threat. All of the educational programs described will include the use of computer modeling to aid in the prediction of system performance.

In an effort to leverage the unique capabilities of the member universities, distance education will be used to allow access to the combined resources of Institute members and eventually to other sites.

\section{BENEFITS}

Educating a cadre of students who are familiar with a common approach and principles of security systems will move the security industry to more uniform solutions, as well as build a strong core body of knowledge. This body of knowledge will incorporate principles of technology, business, and criminal justice to provide a solid basis for design of effective security systems. Commonly used and understood measures will enable users of security systems to evaluate improved performance, allow them to fully understand their risk exposure, and make informed decisions regarding implementation of security systems or upgrades. By focusing on system objectives, security systems will be analyzed in terms of their contribution to the business goals of the facility, as well as their measurable effectiveness. In addition, knowledge of common definitions and measures will better focus security technology research and development on applications with immediate benefit to the security community.

Basic security principles such as detection before delay, protection in depth, use of complimentary sensor technology, balanced protection along all paths to targets, proper installation and maintenance of components and subsystems, and contingency planning in case of loss of components will be an integral part of the programs.

Use of performance measures such as probability of detection for sensors, barrier delay times, and response force time results in an overall assessment of security system effectiveness. This measure helps relate the risk at a facility to threats, targets, consequence of loss, and probability of attack. Students in each of the programs will gain practical experience in the use of computer models used to predict system effectiveness through the use of performance measures. Computer modeling of proposed upgrades will reduce the cost of systems by allowing the evaluation of the upgrade or system prior to implementation and validate expected system performance with respect to the desired objectives.

The Institute will also pursue research and development funding in the areas of physical security, information security, critical infrastructure protection, computer modeling and analysis, and counter-terrorist technology. Individual Institute members are currently working with sponsors from government and industry in areas such as counterterrorism, microelectronics, banking, aviation, and sensor development.

\section{CONCLUSION}

Education programs in security engineering are offered at several US universities including Arizona State University, Louisiana State University, the New Mexico Institute of Mining and Technology, and New Mexico State University. Students in these programs will be taught a common methodology and security principles to apply when designing an integrated security system. The programs will incorporate aspects of technology, criminal justice, and business to provide graduates who are able to make informed decisions concerning the implementation of a security system or upgrades. Students will gain experience in testing system components and determining the performance measures for these components, and apply these performance measures through the use of computer models to predict overall system effectiveness. In this way, effective decisions regarding the expenditure of limited dollars can be made based on expected system improvement and risk reduction.

The unique expertise of the members of the Institute will be leveraged using distance learning where possible. Members of the Institute will also engage 
in research and development of security systems and components for application in a variety of areas including physical security, information security, critical infrastructure protection, computer modeling and analysis, and counter-terrorist technology.

Sandia is a multiprogram laboratory operated by Sandia

Corporation, a Lockheed Martin Company, for the United States Department of Energy under Contract DE-AC04-94AL85000. 